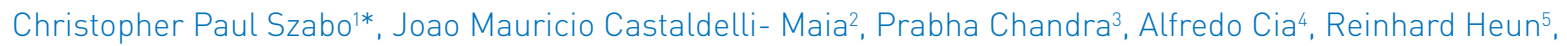
Dusica Lecic-Tosevski ${ }^{6}$, Michelle Riba ${ }^{7}$ Peter Tyrer ${ }^{8}$

\title{
Scientific publishing: a developmental role for the World Psychiatric Association
}

\author{
'Department of Psychiatry, University of the Witwatersrand, Johannesburg, South Africa. \\ ${ }^{2}$ The ABC Centre for Mental Health Studies, Santo André, SP, Brazil \\ ${ }^{3}$ National Institute of Mental Health and Neuroscience, Bangalore, India \\ ${ }^{4}$ Anxiety Disorders Clinic And Research Center, Buenos Aires, Argentina. \\ EUniversity of Bonn, Germany \& Royal Derby Hospital, United Kingdom \\ ${ }^{6}$ Institute of Mental Health, Serbian Academy of Sciences and Arts, Belgrade, Serbia \\ 'Department of Psychiatry, University of Michigan, United States of America \\ IImperial College, London, England \\ *email: Christopher.szabo@wits.ac.za \\ DOI: $10.2478 / g p-2018-0003$
}

Scientific publishing is a cornerstone of clinical practice. Credible content is critical, and sources of such content equally so. A major challenge confronting researchers is publishing their data. Whilst publications are available in abudance, the process of seeing completed research appear in print is more likely the exception and not the rule. Some might argue that the possibility of bad science in print needs to be contained given this attitude. A valid point, assuming all that is published is good science. We have no way of knowing how much good data does not find its way into the scientific literature, but we certainly know that not all data that does is indeed good.

There are numerous reasons why research does not get published, not least of which is that notwithstanding the plethora of available titles in which to publish - it is competitive. Each journal has a specific focus, target market and requirements. There is seemingly a finite capacity, and one cannot, of course, ignore cost. Then come the publishing costs. The publishing industry is for profit, and if not profitable at the very least costs must be covered by the publication if they are not owned by one of any number of publishing houses (where cross subsidization may be possible). Costs and budget have implications for frequency of issues, number of pages per issue, publication format, distribution and so on. Someone has to pay, not only to cover costs of publication but also access to the publication where costs are not covered up front by authors. Certainly the publishing landscape has evolved and will no doubt continue to do so.

The issue of access is germane as it speaks to many factors that impact on researchers, both in the so called developed world and most certainly in the developing world (whose countries find themselves known as Low and Middle Income Countries, i.e. LAMIC). With an emphasis on LAMIC, the World Psychiatric Association (WPA) has had an important role to play in recent times. Various operational committees and task teams under the guidance of various secretaries for scientific publications have engaged in activities to address some of the experienced difficulties encountered by LAMIC member societies. These include access to skills, access to credible publishing platforms, and accessing content, to name a few. To this end, various WPA-facilitated developmental agendas have been implemented. These have included WPA hosted workshops aimed at improving quality of local publications (Szabo et al. 2010).

The aim has been indexation in credible scientific databases (Mari et al. 2011). Local policy should ideally be informed by local content. Local content should be available in credible publications that serve not only a local audience. Sharing of credible data cannot simply be a one-way stream from developed to developing world countries as if the developing world has little to offer by way of science. Developed world researchers certainly frequent developing world countries to access clinical material, which invariably is published in journals not necessarily accessible to the population of psychiatrists whose patients comprise the sample. The WPA, through World Psychiatry, might consider having special issues for cross-cultural studies and those that have been conducted in LAMIC.

For local data to be available in credible local publications that serve an international audience, these publications need to be indexed in certain databases. Inclusion in these databases is generally problematic for local publications insofar as 
they struggle to meet the minimum standards required for inclusion. Hence the aforementioned WPA workshops are conducted. To this end, the WPA has through their website - in the past triennium - initiated the development of a database that seeks to include all member society open access publications, i.e. the provision of a platform for dissemination that in effect by passes existing databases to which access can be limited.

Finally, LAMIC researchers struggle to publish in the major publications that inform the discipline. Scientific writing and how to get published is certainly an area where the WPA, in the interests of world psychiatry, has played a role through hosting of targeted workshops with interactive sessions at WPA congresses over the past triennium for junior researchers and so called early career psychiatrists. The aim has been to provide both helpful information as well mentorship, where local mentorship in their home countries is lacking. This could be developed further, e.g. through inclusion of recorded clips on the WPA website by established and previous editors of major journals with tips on choosing the right journal, pitching an article to the right source, giving examples of well written and not so well written articles and how editors think.

If the WPA is to serve the world, it needs to pursue a developmental agenda that is truly global in scope, recognizing the need to close the gap between developed and developing. Specific initiatives have demonstrated a commitment to such an agenda (Szabo et al. 2012). The next triennium of office bearers recently elected at the WPA Congress in Berlin (October 2017) will hopefully continue with such work.

\section{REFERENCES}

Szabo CP, Kieling C, Mari J de Jesus, Herrman H. Promoting editorial capacity in psychiatric journals in low and middle income countries. Workshop at the World Psychiatric Association Congress, Beijing, China, September 2010.European Science Editing 2010 (November); 36(4): 109-110.

Mari J de Jesus, Szabo CP, Wu C, Lam LCW, Wang L, Midin M, et al. Promoting editorial capacity in psychiatric journals in low and middle income countries (LAMIC). African Journal of Psychiatry 2011 (March); 14: 60-62.

Szabo CP, Mari J de Jesus, Kieling C, Herrman H. The role of the World Psychiatric Association in facilitating development of psychiatric publications from low - and middle - income countries. Revista Brasileira de Psiquiatria 2012; 34(1): 12-15. 